\title{
Desmitificación y revalorización de la libertad a través de Girard y Morin
}

\section{Demystification and Revaluation of Freedom through Girard and Morin}

\author{
Agustín Moreno Fernández \\ Universidad de Granada (España) \\ morenofdez@ugr.es \\ Fecha de recepción: 01/12/2018 \\ Fecha de aceptación: 24/07/2019
}

\section{Resumen}

La idea de libertad es fundamental en la Ilustración y en las democracias y hemos de seguir repensándola. La heteronomía mimética y la disolución del sujeto niegan aparentemente la libertad y la autonomía subjetivas en la teoría mimética girardiana. Sin embargo, se demuestra cómo Girard no sólo desmitifica la libertad moderna sino que al enfatizar la dificultad de su ejercicio la revaloriza e invita a la responsabilidad. Proponemos el paradigma de la complejidad de Morin para completar la visión girardiana de la libertad. De este trabajo se concluye que es posible y necesario conciliar: mimetismo humano y emancipación; heteronomía y autonomía; dependencia y libertad; enfoques filosófico, humanístico, científico e interdisciplinar.

Palabras clave: Libertad; Autonomía; René Girard; Teoría mimética; Edgar Morin; Subjetividad.

\begin{abstract}
The idea of Freedom is fundamental in Enlightenment and in democracies and we have to rethink it. The mimetic heteronomy and the dissolution of the subject apparently deny subjective freedom and autonomy in mimetic theory. Nevertheless, we can observe René Girard not only demystifies modern freedom but when he underlines the difficulty for practicing it, he increases its value and invites responsibility. We propose Morin's complexity paradigm for completing the girardian approach about freedom. It is possible to combine: human mimetism and emancipation; heteronomy and autonomy; dependence and freedom; philosophical, humanistic, scientific and interdisciplinary approaches.
\end{abstract}

Keywords: Freedom; Autonomy; René Girard; Mimetic theory; Edgar Morin; Subjectivity. 


\section{INTRODUCGIÓN}

En este trabajo nos proponemos como objetivo principal repensar la libertad a través de dos pensadores de nuestro tiempo: René Girard, con su antropología filosófica mimética y Edgar Morin, con su paradigma de la complejidad. Vamos a adoptar como punto de partida una versión de la teoría mimética que difiere de algunos de los tópicos y generalidades a los que cabe asociarla. Una lectura que no niega el peso preponderante de su diagnóstico pesimista de la modernidad, y que tampoco contradice los principios y postulados mantenidos por Girard. Nuestro cuestionamiento tiene como hitos lo que podríamos llamar las grietas del determinismo mimético; las excepciones y evocaciones que en la obra de Girard hacen referencia a la libertad, la autonomía y la subjetividad, en relación con las dinámicas del mimetismo humano. Esta tarea nos permitirá pensar de qué manera podemos seguir hablando de la libertad y la autonomía después de Girard, ideas que siguen siendo fundamentales para nosotros en el siglo XXI y una cuestión de primera magnitud ética, política, jurídica y humanística. De ahí el interés por repensarlas contando con aportaciones multidisciplinares de las ciencias sociales contemporáneas.

En primer lugar veremos de qué modo y en qué sentido la teoría girardiana permite hablar de libertad y autonomía, a nivel filogenético y ontogenético. Después, ilustraremos las posibilidades de emancipación que serían admisibles desde los parámetros miméticos, incluyendo un tímido planteamiento sobre la construcción de la subjetividad y destacando el papel de la toma de conciencia y del conocimiento. Finalmente, pondremos de manifiesto la aporía en la que incurriría la teoría mimética al hilo de la cuestión de la libertad humana. Llegados a este punto ofreceremos una solución a través de Edgar Morin y apelando también a otros autores.

Las conclusiones más destacables de este trabajo son, por un lado, más allá de una desmitificación de la idea de libertad, su revalorización de acuerdo con aportaciones y resultados de diversas ramas del saber contemporáneo. Por otro, la idea según la cual, para repensar adecuadamente la libertad y la autonomía del sujeto, no sólo es posible sino pertinente y necesario pensar conjuntamente: mimetismo humano y emancipación; heteronomía y autonomía; dependencia y libertad, a través de un amplio enfoque humanístico, filosófico, científico e interdisciplinar.

\section{LIBERTAD EN LA ESPEGIE HUMANA Y EN EL INDIVIDUO}

Girard teoriza acerca de la probabilidad de que muchas comunidades humanas primigenias perecieran en incontrolables crisis violentas y venganzas sin fin y es ahí donde inserta su hipótesis del mecanismo victimario y la tesis del ser humano como vástago de la violencia y de lo religioso, dibujando una humanidad dependiente de las víctimas sacrificiales. Estamos ante una teoría que nos ofrece una doble cara. El grado de autonomía de la especie humana con respecto a otras, emancipándose 


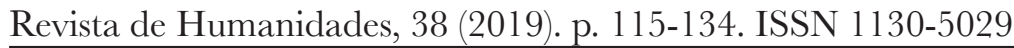

(aunque no totalmente) del régimen de los instintos, la sume en el riesgo de la violencia sin control y de su propio perecimiento. Y la liberación del peligro de sucumbir en el caos del odio y la destrucción, en la lucha de todos contra todos, tendría el precio de la dependencia del mecanismo sacrificial. Una idea de la libertad humana, proveniente de la invalidez del hombre, que ya se hallaría en Rousseau, Kant o Fichte (Boyer, 1985, p. 579).

Las religiones sacrificiales serían el único freno y la única protección de la peor y más temida amenaza que se habría cernido sobre los seres humanos desde la noche de los tiempos: la violencia social. Más aún, las religiones antiguas habrían educado a la humanidad, "arrancándolas de la violencia arcaica" (Girard, 2004, p. 101). La verdad de la humanidad estaría enraizada en los orígenes de cada cultura, tributarios de la violencia colectiva. Para lo mejor y para lo peor los hombres deberían su humanidad a ésta (Girard, 2006b, p. 278). El pensador francés sostiene, frente a modernos e ilustrados, que lo religioso no sólo no es inútil, sino que "deshumaniza la violencia, sustrae al hombre $s u$ violencia a fin de protegerle de ella, convirtiéndola en una amenaza trascendente y siempre presente que exige ser apaciguada por unos ritos apropiados así como por un comportamiento modesto y prudente" (Girard, 1983, p. 143).

Será también a partir de la religión, en un sentido diferente, representado sobre todo para Girard en el cristianismo, desde donde se cuestione la dependencia de los sacrificios, concediéndole así un papel capital en la evolución de la humanidad (Girard, 2007, p. 212). Pero el judeocristianismo no habría sido el único protagonista en esta tarea "humanizadora" o en procurar nuevas cotas de emancipación: "todas las religiones de la humanidad se presentan como etapas intermedias entre la animalidad y la coyuntura de la crisis actual, es decir, nuestra desaparición definitiva o nuestra promoción a formas de conciencia y de libertad que apenas logramos sospechar" (Girard, 1982, p. 483).

Girard, no obstante, reconoce que hay muchas prácticas de lo religioso arcaico que siguen vigentes tras el cristianismo, procedentes de los sacrificios, con un papel indispensable en las sociedades humanas, como los ritos. Sostiene que hay una continuidad en la evolución y en la historia humanas y, a pesar de la irrupción del cristianismo y de su influencia, aquella no se rompe (Girard, 2006b, p. 128), concibiendo nuestra historia como "una espiral abierta hacia lo alto, hacia otra dimensión que no es en absoluto circular. Esta apertura es nuestra libertad y los hombres harían de ella un uso que nadie puede predecir" (Girard, 1996, p. 84)1. Niega que su planteamiento aniquile la acción política o individual y esgrime: "Las instituciones muertas [el sistema ritual y victimario] son atroces y su muerte no

1 En Esprit, Girard además se pregunta de dónde viene esta libertad, si significa que hemos escapado definitivamente de la violencia, problemas ligados a las cuestiones sobre lo judeocristiano. (Aubral et al., 1973, p. 546. Véase también: Girard, 2011, pp. 106-107). 
representa la muerte de lo político, sino al contrario su nacimiento, el nacimiento de la responsabilidad humana" (Dumouchel y Dupuy, 1983, p. 367).

Pasamos ahora a exponer de qué modo cabría hablar de libertad y autonomía a nivel individual, a pesar del poco o nulo lugar que parece concederles la teoría mimética. Cabría pensar que el mimetismo del deseo humano como gran responsable de la violencia que nos abruma es malo (envidias, celos, rivalidades, conflictos). En cambio, el deseo mimético le merece a Girard también el calificativo de "intrínsecamente bueno", asociándolo además a la libertad humana: "si nuestros deseos no fueran miméticos, estarían fijados para siempre en objetos predeterminados, constituirían una forma particular de instinto. Como vacas en un prado, los hombres no podrían cambiar de deseo nunca. Sin deseo mimético, no puede haber humanidad" (Girard, 2002a, p. 33; Williams, 1996, p. 64). Aunque Girard afirma que el deseo mimético es universal y afecta tanto a adultos como a niños, podríamos admitir que los más adultos podrían resistir mejor las malas consecuencias del mimetismo, como en el episodio evangélico de la lapidación fallida de la adúltera, que comentaremos más tarde. Sólo en principio, ya que no establece netas distinciones que separen irremediablemente a tipos de personas que pudieran resistir, a modo de superhéroes y durante toda su vida, los embates del mimetismo. Entre los jóvenes animales y sus modelos adultos existiría un vínculo mimético muy fuerte, incluso indestructible, que se establece al comienzo de la vida y que los etólogos denominan con la palabra "impresión" o "huella" (empreinte). Girard dice que el lenguaje de Shakespeare (a quien le atribuye una maestría inigualable en la descripción de la naturaleza humana), asume este esquema, aunque precisando que los seres humanos, al contrario que los animales, "no están programados de por vida: una vez adultos, pueden rechazar la “impresión" original, o reasumirla a pleno gusto" (Girard, 1990, p. 210).

Empero no todas las ideas de Shakespeare reciben su beneplácito. Le parece que cuando habla de "deseo sugerido" no está del todo acertado. Hablar de deseo sugerido y no de deseo mimético, implicaría "demasiada pasividad", ya que el sujeto debe cooperar activamente con su mediador, y el deseo no sería tan pasivo como sugiere Shakespeare con esta expresión. Curiosamente, realiza un reproche similar pocos años más tarde al concepto de "sugestionabilidad" del psicólogo y neurólogo Pierre Janet (Girard, 1995, pp. 109-125).

Girard insiste en lo que, a su juicio, mostraría continuamente Janet en su obra El automatismo psicológico. Que la imitación es "una asunción de influencia" (Girard, 1995, p. 112). Frente a las mágicas y magnéticas fuerzas del hipnotismo y la sugestión, que sitúan toda la actividad del lado del hipnotizador, Girard se niega a pensar el sujeto como absolutamente pasivo: "La sugestión pura no existe puesto que hay siempre, de la parte del sugestionado, una adopción activa de la sugestión. Janet no me contradiría: afirma, en efecto, que la sugestión no solamente desencadena imágenes y alucinaciones, sino que comporta fenómenos motores, movimientos, actividades. [...] No se puede hablar de autosugestión ya que justamente hay 


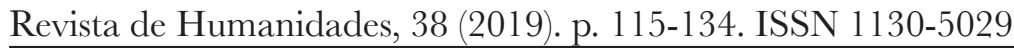

heterosugestión, hay un hipnotizador. No hay más que un solo registro donde situar esta actividad, el de la imitación" (Girard, 1995, pp. 112-113). Así, en tanto que se cuestiona la pasividad del sujeto, se abre camino el aumento del grado de libertad, optatividad y responsabilidad del sujeto a la hora de elegir y adoptar los modelos de imitación (Girard, 1995, p. 116)2: "nadie sabría recibir de otro un deseo hecho por entero y no hay sujeto, por receptivo que sea, que no deba cooperar activamente con su mediador. Ningún individuo puede él solo suscitar deseo mimético en otro, y, si los deseos no cesan de devenir miméticos, esto es posible, incluso en Shakespeare, sin incitación de la parte de los modelos e incluso sin que ellos lo sepan. Hay por tanto, yo creo, buenas razones para hablar de deseo mimético o imitativo más bien que de deseo sugerido" (Girard, 1990, p. 34).

A pesar de que Girard subraya sobre todo (y de modo pesimista) las problemáticas que suscita el mimetismo y su lado violento - como señalan también Jean-Michel Oughourlian (Oughourlian, 2017, p. 79) y Edgar Morin (Morin, 2017, p. 136; Morin, 2001 , p. 100) -, no es menos cierto, como apuntábamos, que contempla la cara positiva de los comportamientos imitativos. El deseo mimético, aunque pueda ser pernicioso si suscita las rivalidades, también sería muy positivo: "no es malo en sí mismo, es incluso muy bueno, y, felizmente, los hombres no pueden renunciar a él más de lo que puedan hacer con la alimentación o el sueño. Es a la imitación a la que debemos no solamente nuestras tradiciones, sin las cuales no podríamos nada, sino paradójicamente, todas las innovaciones a las que hacemos tanto caso hoy día" (Girard, 1996, pp. 55-56).

El mimetismo está presente tras una multitud de fenómenos, pero Girard no sería tan reduccionista como para excluir otras explicaciones, aunque en el pasado pudiese jactarse de ello (Groot, 2008, p. 60; Girard, 1991, pp. 55, 61-62). Afirma, incluso, que él no dice que no haya yo autónomo, sino que "las posibilidades de ese yo autónomo, en cierto sentido, están casi siempre recubiertas por el deseo mimético, y por un falso individualismo en el que el apetito de diferencia tiene, por el contrario, efectos niveladores" (Girard, 1996, p. 24).

¿Cuáles son entonces esas posibilidades de "yo autónomo" de las que Girard habla de pasada? ¿No están tan cerradas, después de todo, las puertas de su teoría a la libertad y la emancipación humanas?

\section{EL SUJETO LIBRE Y AUTÓNOMO}

Eso es lo que se revela al contemplar las matizaciones girardianas, más allá de los planteamientos generales: "En su teoría, parece que los seres humanos no sean ni autónomos - puesto que su deseo siempre es mimético - ni pacíficos - puesto que no pueden evitar la aparición de formas de violencia engendradas por la naturaleza

2 Girard continúa relacionando este antimimetismo de Janet con el platónico. 
mimética de su deseo". (Girard, 2006a, p. 136). Girard no está de acuerdo con la definición y, a pesar de que asuma que el deseo siempre es mimético, responde que "algunos hombres resisten al deseo. Es el interés de ser cristiano. [...] el individuo no está abandonado de pies y manos al deseo mimético. Jesús mismo ha resistido. Hablar de libertad, es evocar la posibilidad que tiene el hombre de resistir al mecanismo mimético". (Girard, 2006a, pp. 136-137).

Precisamente es en la interpretación de episodios narrados en las escrituras judeocristianas donde encontramos las principales consideraciones al respecto de la posibilidad de la libertad subjetiva. Es el caso de la historia de Job. Cuando todos se afanaban en mostrarse atentos y afectuosos con él, los amigos eran muchos. Sin embargo, cuando necesita apoyo, todos le eluden, incluso sus amigos más próximos. Girard muestra que los amigos no eran ajenos en su comportamiento a la imitación de la mayoría de la gente que le era favorable y, después, tampoco lo son cuando todos le vuelven la espalda a Job (Girard, 1989, p. 79). La "inmunidad al mimetismo" sería una "virtud rara y preciosa entre todas", aunque "sólo una gran capacidad de resistencia a los arrastres miméticos puede asegurar esta independencia. Todos los sentimientos miméticos conviven muy bien. Los estúpidos arrebatos de la moda desembocan en las feroces exclusiones de los chivos expiatorios". (Girard, 1989, p. 79). Los amigos de Job no sólo no poseen la virtud, sino que siguen la atracción mimética del comportamiento de la mayoría, sea orientada hacia la repulsión o hacia la adulación (Girard, 1989, p. 80).

Girard se queja de que hay quienes hablan mucho de la libertad y, cuando creen estar enalteciéndola, la estarían banalizando, sin considerar las dificultades que implica ejercitarla. Es, entre otras cosas, lo que el autor expresa a través del episodio de la mujer adúltera a la que van a lapidar ante Jesús ${ }^{3}$. Jesús estaría ante un terrible dilema: si se opone a la lapidación está menospreciando la Ley y, si la aprueba, traiciona sus enseñanzas, dirigidas contra los contagios miméticos y los desbocamientos violentos. Todo el mundo debe tirar piedras a la adúltera en un comportamiento unánime, una violencia ritual mediante la cual la comunidad se reconcilia: "así es como, sin duda alguna, la tesis mimética debe explicar la existencia de una lapidación institucional, tal como se la encuentra codificada mucho más tarde en el Levítico" (Girard, 1996, p. 142). El pensador se detiene en distintos detalles del texto, pero se concentra en las palabras capitales:

¡Que aquel que se crea libre de pecado le arroje la primera piedra!” ¿Por qué la primera piedra? Porque ella es la única decisiva. Aquel que la tire no tiene a nadie a quien imitar. Nada más fácil de imitar que un ejemplo ya dado. Dar uno mismo el ejemplo es una cosa totalmente diferente. La multitud está miméticamente movilizada, pero le queda

3 En toda la obra de Girard, en al menos tres ocasiones el autor se detiene a exponer, analizar y extraer consecuencias del episodio evangélico de la lapidación fallida de la adúltera de Juan 8, 3-11 (Girard, 1995; Girard, 1996; Girard, 2002a; Girard, 2004). 
Revista de Humanidades, 38 (2019).p. 115-134. ISSN 1130-5029

un último umbral que franquear, el de la violencia real. Si alguno tirara la primera piedra, inmediatamente después lloverían las piedras (Girard, 1996, p. 143).

La primera piedra sería decisiva, la más difícil de lanzar porque sería la única que carece de modelo. Cuando Jesús llama la atención sobre ella de forma explícita, estaría reforzando y magnificando el último obstáculo que se opone a la lapidación. De manera que cuanto más piensen quienes van a tirar la primera piedra, en la responsabilidad que asumirán si lo hacen, sería más probable que no lo hiciesen. En cambio, una vez lanzada la primera piedra, la segunda, la tercera y las sucesivas llegarían más rápido, ya que cada vez los demás tendrían más modelos que seguir: "cuanto más se multiplican los modelos, más se acelera el ritmo de la lapidación" (Girard, 2002a, 82-83). Se haría patente que se requiere un modelo mimético para lanzar las piedras. También en el ejemplo inverso de la inicial resistencia de los efesios a hacerlo, en el caso del relato que narra la incitación de Apolonio de Tiana para apedrear a un mendigo ${ }^{4}$. La primera piedra no sería un asunto de mera retórica (Girard, 2002a, p. 82).

Girard interpreta que Jesús habría trascendido la Ley, pero apoyándose en lo que la legalidad tendría de "más humano, de más ajeno al mimetismo de la violencia", en previsión de las falsas denuncias, para dificultarlas lo más posible: "la obligación impuesta a los dos primeros acusadores de tirar las primeras piedras. La Ley priva a los delatores de modelos miméticos" (Girard, 2002a, pp. 84-85; Girard, 2004, p. 41).

El autor pone al acento en "los mejores" que, entre la multitud, considera que cuentan con tiempo para escuchar a Jesús y se examinan a sí mismos: "Para lapidar a una víctima con rectitud de intención, es necesario creerse diferente de ella, y la convergencia mimética [...] se acompaña de una ilusión de divergencia. Es la convergencia real, combinada con la ilusión de divergencia, la que desencadena lo que Jesús trata de prevenir, el mecanismo del chivo expiatorio" (Girard, 1996, p. 144). También Edgar Morin se ha detenido a comentar la dimensión ética del autoexamen al que invita Jesús con "la primera piedra" (Morin, 2013, p. 40)5.

4 Girard compara dos lapidaciones. Apolonio de Tiana, famoso gurú del siglo II, anima a los efesios a lapidar a un mendigo harapiento, supuestamente endemoniado, para poner fin a una peste. Consigue que alguien tire la primera piedra y, con ella, la lapidación y el "milagro" de la extinción de la epidemia. Suscitado el primer modelo de alguien que lanza la piedra, todo es más fácil. En la lapidación de la adúltera, finalmente esta no se lleva a cabo, impedida por Jesús, invitando a que aquel que esté libre de pecado tire la primera piedra. La falta de modelo alguno que lance la piedra y el número en aumento de potenciales modelos que se van, desactivan la lapidación. (Girard, 2002a, pp. 73-75). Girard aprovecha para criticar la idealización de la cultura grecorromana. (Girard, 2004, p. 41).

5 Aunque para Morin Jesús es totalmente humano (Girard, reconoce en cambio también en él al Cristo), dice no ser capaz de elucidar su misterio y de dónde vendría su sentido humano del perdón al pecador, desconocido en judíos, griegos y romanos. Con la exhortación de tirar la primera piedra: "pide al lapidador volverse sobre sí mismo y, tomando conciencia de que él mismo podría ser condenado por otros pecados, renunciar al castigo; lo que se nos pide es una parte de lo que he llamado la auto-ética: el auto-examen, la fuerza de la duda vuelta sobre sus propios actos”. (Morin 2013, pp. 39-40). 
¿Qué ha sucedido con el primero, con los primeros que han dejado caer sus piedras renunciando a lapidar a la mujer adúltera? Para Girard no hay duda, estaríamos ante una muestra de un genuino comportamiento individual, aunque cada vez menos individual, en la medida en que esté motivado por cada vez más ejemplos de modelos que renuncian a la lapidación, y menos por una reflexión individual suscitada por las palabras de Jesús:

no se hace verdaderamente individuo más que aquel que, separándose de la multitud, escapa a la unanimidad violenta. Todos no son capaces de tanta iniciativa. Aquellos que son capaces se separan los primeros y, haciendo esto, impiden la lapidación. Esa imitación comporta una dimensión auténticamente individual. [...] Para los primeros imitadores de aquellos que han comenzado a marcharse, se puede hablar todavía de decisión, pero en un sentido que se debilita cada vez más rápido a medida que el número de decididos aumenta. La decisión inicial, desde que es imitada, vuelve a ser rápidamente contagio puro, mecanismo social (Girard, 1996, pp. 144-145; Girard 1995, pp. 123-124).

El simbolismo de la primera piedra seguiría vivo, porque "la definición mimética de los comportamientos colectivos continúa siendo tan válida como hace dos mil años" (Girard, 2002a, pp. 83-84). Tanto para mal, como ilustraría Apolonio de Tiana incitando a la lapidación del mendigo. Como para bien, como en la lapidación abortada de la adúltera, ya que incluso la renuncia al mimetismo violento se expandiría transformándose en mecanismo social o mimetismo ciego.

Girard afirma explícitamente que "no es necesario concluir que [la teoría mimética] niega la libertad individual" (Girard, 1996, p. 145). Le resultaría excesivo decir que el bien sólo se impone por el mimetismo. Tampoco afirma que aquellos que dan los primeros pasos deben ser necesariamente los "jefes" y el primer paso "puede consistir en aceptar seguir, en lugar de dirigir", como en el episodio de la adúltera (Girard, 1996, p. 147). Si es posible cambiar, no estamos condenados a ideas, opiniones o deseos fijos. Lo ejemplificarían tanto los efesios que, aunque en frío y sin motivos, no se deciden a asesinar al mendigo, pero acaban por adoptar el modelo de Apolonio que les anima a hacerlo; como la masa que finalmente, siguiendo el modelo de Jesús, se detiene.

Girard no sólo no negaría la libertad, sino que la valoraría más que otros. Porque asevera que sitúa la libertad en su justo y difícil contexto, el de los contagios miméticos. Advierte la lección moral y política que habría que sacar del gran riesgo que entraña el mimetismo, para tomar decisiones en una situación en la que el sujeto está particularmente afectado por un grupo o multitud:

es necesario no fiarse del mimetismo. Esta lección es muy ciertamente democrática en la medida en la que ella reconoce que los movimientos de multitud oscilantes son lo que constituye el peligro. [....] Los modelos de la democracia representativa en el siglo XVIII, en Montesquieu o en los ingleses, no proceden, como se ha dicho, de una 
Revista de Humanidades, 38 (2019).p. 115-134. ISSN 1130-5029

voluntad de quitar al pueblo del poder, sino que buscan evitar los efectos miméticos de multitud. La verdadera democracia consiste precisamente en conciliar la participación de todos los individuos en la vida política, sin caer en los efectos miméticos de embriaguez colectiva que todo régimen totalitario utiliza y del cual el texto bíblico nos habla constantemente (Dumouchel y Dupuy, 1983, p. 367).

Escapar al mimetismo sería algo propio de genios, -caso de los grandes novelistas- y de santos (Girard, 2007, p. 235), pero ni siquiera ellos estarían exentos de las dinámicas del deseo y de la imitación: "incluso los mejores seres humanos son sensibles a las polarizaciones miméticas" (Girard, 2002b, p. 185). En cualquier caso, una resistencia meramente individual que no fuera más allá, no sería útil, en lo que a la contención de las escaladas de violencia y de las amenazas apocalípticas se refiere. Además de afirmar que seríamos libres porque siempre podríamos convertirnos $^{6}$, el autor afirma que lo somos "porque nos negamos a sumarnos a la unanimidad mimética" (Girard, 2004, pp. 107-108). Esta resistencia debería ser colectiva, preferiblemente precedida de un personal ejercicio de reflexión y de toma de conciencia y, para ser efectiva, todos los hombres deberían darse la mano (Girard, 1996, p. 197).

\subsection{Libertad, toma de conciencia y conocimiento}

El relato aludido nos haría ver la identidad de los comportamientos sociales. Todos serían miméticos, aunque difieran entre sí y la proporción de mecanismo y de libertad que comportan varíe infinitamente. A pesar de todo, Girard hace gala del espíritu ilustrado. Confía en el conocimiento como forma de resistencia ante el mimetismo social, ya que todo lo que necesitamos conocer para resistir automatismos sociales y contagios miméticos sería accesible al conocimiento (Girard, 1996, p. 146; Girard 2007, p. 11).

El filósofo desgrana una incisiva crítica al relativismo que no obvia la diversidad cultural y admite lo que denomina "relativismo social" (el cuestionamiento de la verdad de la acusación de un colectivo contra la verdad de una víctima) (Moreno, 2010). Esta crítica más enfocada al terreno etnológico se subsume en una impugnación más amplia del relativismo epistemológico, asociado a las corrientes filosóficas e intelectuales propugnadoras del nihilismo, el escepticismo o la renuncia al conocimiento de lo real. De imponerse, esta visión daría al traste con la interpretación de los textos históricos de persecución y de los mitos, en los que Girard ausculta la realidad y la verdad de víctimas de horrendas persecuciones y violentos crímenes. También liquidaría la pretensión de establecer una jerarquía en la que la versión del

6 El concepto de conversión es principal en la teoría mimética: "todo el análisis del deseo mimético está al servicio de la conversión” (Girard, 1991, pp. 75-76). Cabría hablar de varios tipos de conversión (Moreno, 2014). 
verdugo y la de la víctima no valen lo mismo. Es, en este sentido, que Girard pretende salvaguardar la que considera la herencia, sobre todo judeocristiana y del espíritu crítico moderno, del saber de interpretación de los estereotipos de la violencia y la persecución. Esto, frente a la tentación a dimitir de los logros históricos alcanzados que estaría significada, entre otras cosas, por la renuncia de la ruptura del círculo hermenéutico, como la entiende el pensador:

¡La cuestión es formidable! Puesto que es evidente que transgrede todas las reglas de la interpretación intelectual, del estructuralismo o del post-estructuralismo. Diría que la ruptura del círculo hermenéutico, a mi modo de ver, está ya hecha. Ha tenido lugar en el momento en el que, en Occidente, hemos logrado leer algunos sistemas de representación victimaria debilitados. Hago referencia a la caza de brujas o a la visión de los perseguidores en los fenómenos de multitud. Si leen un proceso de bruja, verán que está generalmente de acuerdo con sus acusadores, dicho de otra manera, nos encontramos ante un texto de acusación monolítica, unánime. A partir del siglo XVII, los historiadores dicen: es de broma, incluso si la bruja cree, nosotros no creemos y nosotros lo sabemos. Esto es fundamental para todo el espíritu crítico moderno, y no podemos relativizar este fenómeno. Es aquí que se hunde toda la crítica relativista, la que dice: toda interpretación de un texto es un nuevo texto, la interpretación del señor $\mathrm{X}$ vale la del señor $\mathrm{Y}$, no hay mejor interpretación. [...] Reconozco que no hay aquí una prueba científica, en un sentido no hay más que un acto de fe. Pero es un acto de fe en la historia y en la acción de los hombres [...]. Lo que no va del todo en contra de la libertad o de la acción política, contrariamente a lo que a menudo me han reprochado (Dumouchel y Dupuy, 1983, pp. 366-367).

Abordamos ahora un ámbito más cotidiano en el que el potencial desmitificador de la teoría mimética también tendría un papel y la toma de conciencia que procura posibilitaría ganar cuotas de libertad y responsabilidad. Sólo la conciencia de la inminencia del peligro de la propia violencia humana, o de los desastres naturales que pueda ocasionar nuestro modo de vida, podría volver nuestros comportamientos miméticos en actos responsables (Girard, 2007, p. 143). El único medio de dar el paso siempre posible, dice Girard, de la reciprocidad a la relación, del contagio negativo al contagio positivo consiste en "reconocer la imitación y su ambivalencia" y lo ve ejemplificado de forma insuperable en la imitación de Cristo o de modelos semejantes (Girard, 1996, p. 198)7. Este reconocimiento también consistiría en pensar una posible mutación interna del principio mimético, que sería "la renuncia a la autonomía de nuestro deseo" (Girard, 2007, p. 232). También habría que renunciar a la ilusión de la existencia de un espacio no sacrificial, como él mismo habría hecho (Moreno, 2016). Girard, lejos de querer justificar la violencia, aboga por una "constante lucidez de su carácter radical", ya que solamente a partir de esta

$7 \mathrm{Y}$, sin embargo, cualquier modelo de imitación no está exento de problemas. Incluso la bondad o la humildad pueden convertirse en motivo de rivalidad mimética. 


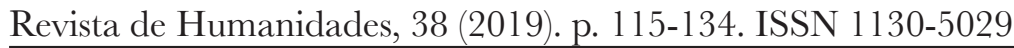

conciencia sería posible cohabitar con lo que, al mismo tiempo, nos define como seres humanos y nos pone en riesgo (Girard, 2006a, p. 22).

La teoría mimética no sólo arroja luz sobre la violencia, sino antes bien sobre el deseo, sobre el mimetismo que sería fundamental tanto en la primera, como en el segundo y que tampoco cabría entender de forma escindida. El conocimiento de la regulación mimética permitiría actuar con mayor habilidad y mayor libertad y la teoría mimética sería un saber responsabilizante (Dumouchel y Dupuy, 1983, p. 369).

El propio autor se interesa en los años noventa por el problema de la anorexia, atraído por el lado contagioso y mimético del fenómeno y el vínculo con modas, modelos y medios de comunicación. En Stanford trata con un estudiante conocedor de la teoría mimética, que le informa sobre la presión social favorable a la anorexia y a la preocupación por la delgadez. A pesar de su tentación a hacer un régimen, "la conciencia que él tenía del carácter colectivo y social de la cosa se lo impedía. Él no quería sucumbir a esta presión, se sentía víctima de un fenómeno social que no controlaba" (Girard, 2008, p. 92).

Al hilo de unas palabras sobre Shakespeare y cómo trata éste a César en su obra, Girard también nos avisa del engañoso sentimiento de autonomía, tras el cual puede esconderse lo contrario: mientras "más el dictador se iza sobre lo alto de otros hombres y tiene un sentimiento subjetivo mayor de autonomía, es menos autónomo" (Girard, 1990 , p. 245). El pensador es consciente de que una aparente toma de conciencia no lleva necesariamente a superar las dificultades. Incluso puede agravarlas. Es lo que ejemplifica nuevamente Shakespeare, cuando sus personajes muestran que perciben claramente aspectos del deseo que otros son incapaces de comprender. Tienen más experiencia y pueden anticipar los efectos de los principios miméticos. Sin embargo, al contrario de lo previsto y de lo deseable, este conocimiento superior no disuelve los problemas, sino que los acrecienta: "su aumento de consciencia agrava incluso su condición por una razón fuertemente simple: está al servicio del deseo" (Girard, 1990 , p. 107) ${ }^{8}$. En un sentido similar se expresa E. Gans, cuando asevera que "el deseo, que no comporta en él mismo el momento reflexionante, no se dirige más que hacia su objeto; ignora en principio al Otro y no sabría por tanto tomar la medida de la distancia de aquel al objeto" (Gans, 1973, p. 577).

\section{DE LA DESMITIFICACIÓN A LA REVALORIZACIÓN Y SOLUGIONES AL DÉFICIT TEÓRICO DE GIRARD}

A la vista de lo aquí expuesto, debemos considerar a Girard, no sólo a través de sus mordaces críticas al racionalismo, al humanismo moderno y al proyecto de la Ilustración. También hemos de tener en cuenta: su confianza en la razón; su

8 Se trata de Claudio y su rivalidad con el Príncipe en Mucho ruido para nada. 
aspiración a dar cuenta de lo real a través del conocimiento; su afán por un saber intercomunicable que considera las diferencias culturales, pero trascendiéndolas en un horizonte universal; $\mathrm{y}$, en este caso que nos ocupa ahora, su paradójica revalorización de la aspiración al ejercicio de una subjetividad autónoma y libre, que nunca puede desentenderse de la heteronomía interdividual del mimetismo tendente al conflicto. Sin embargo, encontramos un escollo. Ciñéndonos a los que consideramos que son los elementos principales, ¿es posible conciliar el cuestionamiento de la concepción de la subjetividad moderna con la aspiración a la autonomía?

Una de las señas características de la teoría mimética es la deconstrucción del sujeto en favor de la psicología interdividual (Girard, 1982), cuestionando la noción misma de sujeto. Algo que Girard parece no destacar cuando no renuncia a la concienciación, a la responsabilización y al auto-examen, de una subjetividad con margen para ser autónoma. Como en el caso de la multitud perseguidora de la mujer adúltera, en el que algunos individuos realizan un ejercicio de genuina subjetividad individual, autorreflexiva, libre y responsable, yendo contracorriente de la polarización mimética colectiva contra la acusada. Unas pretensiones (deconstruir el sujeto y apelar a la subjetividad autónoma) que resultan antitéticas.

El déficit teórico de Girard abarca dos planos: la ausencia de problematización de la cuestión ${ }^{9}$ y la falta de vías de salida y soluciones. Sobre lo primero, vemos una colisión entre la deconstrucción girardiana del sujeto como estructura fantasmal trabada de relaciones interdividuales (la heteronomía mimética) y la aspiración a la autonomía o la libertad subjetivas. Podríamos decir que esta, como otras renuncias de la noción de sujeto, como señala A. Renaut, lleva consigo el hundimiento de los valores del humanismo, lo cual choca con la exigencia de autonomía, la experiencia moral, ciudadana y el sistema de conceptos de los valores democráticos que nos remiten a la idea de sujeto (Renaut, 2010, pp. 31-35). Se trata de una situación esquizofrénica, diagnostica E. Morin, en la que hay un divorcio total entre la visión subjetiva, "vivida", de creencia en una libertad relativa y responsable, y la visión "científica" en la que autonomía, individualidad y sujeto desaparecen y donde priman los determinismos (Morin, 1983, p. 317).

El intento de resolución de esta problemática, pasa por identificar no sólo la carencia de un diagnóstico y de su solución en Girard, sino también su afán y su insistencia en negar que la teoría mimética acabe con la posibilidad del yo autónomo o con la libertad. Es más el pensador tiene en cuenta el drama del sujeto moderno, su sufrimiento, sus ensoñaciones miméticas, sus enajenaciones, e invita al ejercicio del auto-examen, la toma de conciencia, la resistencia al mimetismo y la

9 Así se pone de manifiesto en la entrevista de J. Williams cuando, en paralelo a la alusión de Girard a la ética y a la fe cristiana en tanto que asociada a la "salida de la masa", al entrevistador le parece irónica, y hasta contradictoria, esta vinculación por aquel que precisamente ha criticado duramente la exaltación moderna del yo. (Williams, 1996, pp. 278-279). 


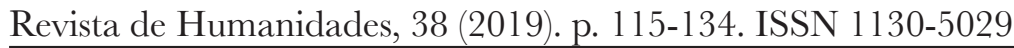

responsabilidad moral. Bajo la óptica de Renaut, incluso en esta crítica del sujeto ${ }^{10}$, habría implícitamente una valoración del sujeto, de la identidad y del dominio de sí, coincidente los valores del humanismo moderno (Renaut, 2010, pp. 32-34).

Pasamos al segundo punto, constatando con Gomá Lanzón que, a través de la revisión de una concepción de la imitación asociada al infantilismo, así como de la revisión de la concepción moderna de un sujeto que se pretende radicalmente autónomo, es posible armonizar la imitación con la emancipación ilustrada del sujeto. Máxime cuando ésta también sería una disposición de ánimo susceptible de imitarse, al igual que se imitan las leyes encarnadas en los prototipos de quienes las cumplen. De este modo, podrían revisarse, además, el lema kantiano e ilustrado de la salida de la minoría de edad y la exhortación a atreverse a pensar sin la guía del otro, rechazando la presuposición de un sujeto monádico, aislado y a-histórico, asumiendo que la influencia de los otros no sólo se produce durante la infancia. La mayoría de edad, dice Gomá, no estaría en la emancipación de los modelos, sino en el juicio autónomo de nuestra heteronomía, en la asunción de la racionalidad del deseo que nos une a ellos, advirtiendo que: "hay que retener la tesis de René Girard según la cual la pretendida autonomía ilustrada-romántica del sujeto, la idea de un yo original y libre, es sólo una ilusión, porque de hecho, dicho sujeto juzga y desea siempre según otro, mediador o modelo, al que imita" (Gomá, 2005, pp. 520, 516-517).

A través de las reflexiones de E. Morin encontramos un marco teórico más amplio para la antropología mimética y para tratar las problemáticas cuestiones de la autonomía y la libertad. Morin concibe las posibilidades de las libertades humanas a través de sus dependencias ecológicas, biológicas, sociales, culturales, históricas... integrando lo genético, lo cultural y lo social, e impugnando tanto las concepciones metafísicas y espiritualistas asociadas a un sujeto abstracto y descarnado, así como las concepciones deterministas fisicistas y mecanicistas, deshumanizantes e ignorantes de la complejidad bio-antroposocial. Nociones como las de autonomía, individuo, sujeto o libertad estarían enraizadas y sería posible clarificar sus condiciones físicas, biológicas, neurocerebrales y sociológicas sin tener por qué caer en reduccionismos, ya sean pangenetistas o absoluticen la importancia del medio (Morin, 2000, p. 1).

De esta manera, Morin no sólo desmitifica la autonomía, sino que la re-sitúa, pasando de la idea de la imposición de fatalidades del medio exterior a los seres vivientes - no hablamos sólo de seres humanos - a una concepción de la autonomía dependiente. Morin deja atrás la esquizofrenia, eliminando el falso dilema entre la libertad psíquica y el nivel cultural, y el determinismo biológico y material. Asume en la autonomía de un ser viviente su dependencia existencial de todo lo que es necesario para su autonomía, así como todo lo que amenaza a esta.

10 Como cuando diagnostica la inhabitabilidad del yo en un sentido amplio y particularmente moderno o contemporáneo, ya apuntado por san Agustín o Pascal. (Girard, 2008, p. 56). 
La libertad humana como emergencia no sería ajena al circuito de dependencias y autonomías de la vida animal, y al aparato neurocerebral animal y sus capacidades y aptitudes. Morin, como Girard, aunque más profundamente que él, amplía el enfoque de las ambivalencias de la naturaleza humana, así como de la autonomía y la libertad, desde la paradójica autonomía de la vida, desde el nivel molecular hasta los productos míticos e ideológicos de la mente humana. Nos hace ser conscientes de que: poseemos los genes que nos poseen y sufrimos sus determinaciones, gracias a las cuales existimos; hacemos la historia que nos hace; dependemos de la sociedad, la cual depende de nosotros. O de que la autonomía individual sólo se forma y se mantiene gracias a la dependencia genética y ecológica, opuestas y unidas en ella. Para Morin, como para Girard, también es importante, y juega en favor de la autonomía, esta toma de conciencia.

Asistir a cómo la libertad, la autonomía, o la subjetividad, son dinamitadas como propiedades metafísicas, no implica que haya que dejar de apelar a ellas, o dejar de invocar la responsabilidad moral o la emancipación del sujeto. Al contrario, una vez desmitificadas y re-situadas, cobran un nuevo y brillante valor y requieren de nosotros más inteligencia, esfuerzo y responsabilidad para ejercerlas.

Estamos de acuerdo con Gomá, en que no sólo es posible esta armonización, desechando las ideas preconcebidas y reduccionistas acerca de la imitación, sino que del lado de la axiología ilustrada, en la medida en que pretenda ser presentada aún hoy día como legítima o en vigor, habrá de asumir evidencias científicas y antropológicas como la del papel fundamental de la imitación en la ontogénesis y en la vida social. De lo contrario, su concepción del sujeto y sus valores permanecerán como algo inasumible, anacrónico y supersticioso. La respuesta a la pregunta de si es imposible ser autónomos imitando a otros no sólo es negativa, sino que una aspiración a la autonomía que no tuviese en cuenta la imitación sería vana e ilusoria. Aunque aquí no las hemos explorado, la teoría mimética critica igualmente toda una gama de ingenuas formulaciones del sujeto idealistas, románticas, existencialistas, postmodernas... que, a través de diversos términos (esencia, originalidad, autenticidad, diferencia), lo caracterizan como entidad autónoma y libre, sin subrayar la alteridad, las dependencias y los condicionamientos miméticos.

Volvemos ahora a Girard, con el ánimo de salvar la falla que detectamos en su pensamiento, entre la radicalidad de sus tesis acerca del mimetismo, y su negación de que éstas impliquen una renuncia total a hablar de sujetos libres y autónomos, aunque obviamente siempre estarían condicionados. En la siguiente reflexión, al hilo de la escena de la adúltera, no quiere ser cándido ni idealizar el comportamiento aparentemente maduro yresponsable de la multitud que "decide" no apedreara la mujer:

Situando la decisión verdadera en su contexto verdadero, el de los contagios miméticos por todas partes y siempre triunfantes, esta teoría da a lo que no es mecánico y sin embargo no difiere del todo en su forma de lo que lo es, un relieve que la libre decisión 
Revista de Humanidades, 38 (2019).p. 115-134. ISSN 1130-5029

no tiene en los pensadores que tienen siempre la libertad en la boca y de este hecho mismo, creyendo exaltarla, la devalúan completamente. Si se glorifica lo decisivo sin ver lo que lo hace casi imposible, no salimos jamás de la metafísica más hueca (Girard, 1995, p. 124).

$\mathrm{Su}$ intención es clara y vemos aquí tres elementos girardianos con respecto a los ideales modernos de libertad y autonomía: 1) desmitificación, cuestionando su pretensión ilusoria como facultades descarnadas e incondicionadas; 2) re-situación, asumiendo el magma mimético interdividual, señalando la dificultad de resistir el mimetismo en sus efectos perniciosos y poniendo de manifiesto la imitación aún en los comportamientos meritorios y nobles; 3) revalorización, ponderando el gran valor de la libertad que no sería tan fácil y accesible. Girard pretende así salir "de la metafísica más hueca". Sin embargo, no podemos soslayar la carencia girardiana de una articulación teórica explícita que reconciliase el condicionamiento mimético, con la apertura a la libertad y a la autonomía subjetivas, eliminando la esquizofrenia diagnosticada por Morin, de la que creemos que no estaría exenta la teoría mimética. Consideramos el paradigma de la complejidad de Morin apto para solventar el déficit teórico de Girard.

En línea con Morin, la filósofa de la educación Marie Louise Martínez advierte sabiamente que sólo cabe hablar de una autonomía que es dependiente. Es decir, a través de sus condicionamientos biológicos, cerebrales, corporales, históricos, sociales, culturales..., frente al trampantojo de la ingenua o pervertida mera asociación de la libertad o la autonomía, con la expansión sin límites de la voluntad o de los deseos, impugnando cualquier tipo de ley, norma o restricción:

Una visión simplista de la modernidad de la Ilustración ha autorizado la ilusión según la cual, a medida que nos alejáramos de la heteronomía de las sociedades tradicionales, nos encaminaríamos, lógica y racionalmente, hacia la autonomía democrática y la racionalidad triunfante. [...] La postmodernidad actual persistiría en el error al reivindicar una deconstrucción perpetua de las instituciones. La teoría mimética, por el contrario, escapa a esta ilusión gracias a la lógica del esquema mimético en su complejidad: se critica la violencia heteronómica de lo sagrado arcaico con sus diferenciaciones y sugerencias, pero cuando los ritos y los tabúes disminuyen, es la violencia anómica la que anula toda diferenciación. [...] No basta con escapar de la heteronomía para alcanzar la autonomía, aún hay que desbaratar las trampas de la anomía (Martínez, 2006, pp. 184-185).

Martínez también considera que no hay que confundir autonomía con autosuficiencia, individualismo, solipsismo o egocentrismo. Que sólo cabe aspirar a la autonomía junto con la solidaridad y el vínculo interpersonal como fundamento y origen; como proceso en pos de una libre elección de nuestros modelos y contra los efectos perniciosos de la reciprocidad mimética violenta. Una liberación que, para Girard, sólo parecería posible mediante la acción del Espíritu y una progresiva 
conversión personal, pero que para Martínez puede favorecerse mediante la acción educativa (Martínez, 1996, pp. 226-229). Por su parte, el neuropsiquiatra Oughourlian no cuestiona que el mimetismo se conciba en cierto sentido como alienación. Pero sitúa esta, más bien, en quienes defienden una idea de la libertad como facultad inherente, asociada a la anterioridad de "mi deseo" sobre los otros y a su predominio sobre el deseo de otros, obviando el mimetismo humano. La libertad, precisamente, sería una conquista, una ascética, una sabiduría que comenzaría asumiendo su suelo nutricio de heteronomía (Oughourlian, 2009, pp. 55-56) ${ }^{11}$ y que se edificaría en un continuo ejercicio de responsabilidad.

Creemos que haber repensado la idea de libertad a través de la teoría mimética nos ha permitido: conocer mejor el pensamiento de René Girard; desmitificar la libertad como atributo metafísico y, a la vez, revalorizarla una vez subrayada la heteronomía mimética como su otra indisociable cara, asumiendo las dificultades que entraña aspirar a ella y el papel del conocimiento y la conciencia para cultivarla. Pensamos, también, que la falla teórica de la teoría mimética, entre la deconstrucción de un sujeto radicalmente mimético y la apelación a una subjetividad libre, autónoma y responsable ha quedado salvada. Asimismo, finalmente, consideramos que los planteamientos expuestos son una muestra de que podemos pergeñar estudios e investigaciones, en los que el concurso de las humanidades y las diferentes ciencias y saberes sirven para repensar ideas y cuestiones fundamentales como la de la libertad, tanto en perspectiva histórica, como interpelados por nuestro contexto contemporáneo.

\section{BIBLIOGRAFÍA}

Aubral, François; Deguy, Michel; Domenach, Jean-Marie et al. (1973). Discussion avec René Girard. Esprit, n 429, pp. 528-563.

Boyer, Alain. (1985). Sacrifice et réfutation. En Dumouchel, Paul. (dir.). Violence et vérité autour de René Girard. Paris: Grasset, pp. 569-589.

Dumouchel, Paul, Dupuy, Jean-Pierre (eds.). (1983). L'auto-organisation de la physique au politique. Paris: Seuil.

Gans, Eric (1973). Pour une esthétique triangulaire. Esprit, n 429, pp. 564-581.

Girard, René (1982). El misterio de nuestro mundo. Claves para una interpretación antropológica. Salamanca: Sígueme.

Girard, René (1983). La violencia y lo sagrado. Barcelona: Anagrama.

11 La libertad como cuestión problemática está presente en una de las últimas obras de Oughourlian. Allí expone dos ámbitos principales para ejercerla partiendo de la asunción del mimetismo del deseo y su dimensión rivalitaria y conflictiva: la elección consciente de los modelos de imitación y el esfuerzo por no rivalizar ni dejar que los conflictos aniden en las relaciones interpersonales. (Oughourlian, 2017). 


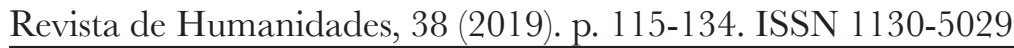

Girard, René (1985). Mentira romántica y verdad novelesca. Barcelona: Anagrama.

Girard, René (1986). El chivo expiatorio. Barcelona: Anagrama.

Girard, René (1989). La ruta antigua de los hombres perversos. Barcelona: Anagrama.

Girard, René (1990). Shakespeare: les feux de l'envie. Paris: Grasset.

Girard, René (1991). Sobre ídolos y sacrificios. René Girard con teólogos de la liberación. San José, Costa Rica: Ed. Dei.

Girard, René (1995). Automatismes et liberté. En: Grivois, Henri; Dupuy, Jean-Pierre (dir.). Mécanismes mentaux, mécanismes sociaux. Paris: La Découverte, pp. 109-125.

Girard, René (1996). Cuando empiecen a suceder estas cosas. Madrid: Encuentro.

Girard, René (2002a). Veo a Satán caer como el relámpago. Barcelona: Anagrama

Girard, René (2002b). La Voix méconnue du réel. Une théorie des mythes archaïques et modernes. Paris: Grasset.

Girard, René (2004). Los orígenes de la cultura. Madrid: Trotta.

Girard, René (2006a). Les origines de la culture. Paris: Hachette-Littératures.

Girard, René (2006b). Aquel por el que llega el escándalo. Madrid: Caparrós.

Girard, René (2007). Achever Clausewitz. Paris: Carnets Nord.

Girard, René (2008). Anorexie et désir mimétique. Paris: L'Herne.

Girard, René (2011). Sanglantes origines. Hamerton-Kelly, Robert (ed.). Flammarion.

Gomá Lanzón, Javier (2005). Imitación y experiencia. Barcelona: Crítica.

Groot, Geer (2008). Emociones de segunda mano. Conversación con René Girard. En Id. Adelante, ;contradígame! Filosofía en conversación. Sequitur: Madrid, pp. 55-72.

Martinez, Marie-Louise (1996). Vers la réduction de la violence à l'école. Lille: ANRT.

Martinez, Marie-Louise (2006). Aproximación antropológica a la violencia en la escuela y en el deporte. Anthropos, no 213 , pp. 16-34.

Moreno Fernández, Agustín (2010). René Girard y su crítica de la etnología multiculturalista y relativista. Gazeta de antropología [en línea], $\mathrm{n}^{\circ} 26$ (2), art. 28. $<$ http://www.gazeta-antropologia.es/?p=1722> (Última consulta: 18/07/2019).

Moreno Fernández, Agustín (2014). La conversión en la teoría mimética de René Girard. Pensamiento, $\mathrm{n}^{\circ} 263$ (vol. 70), pp. 277-305. $<\mathrm{https}$ ://revistas.upcomillas.es/index. php/pensamiento/article/viewFile/4681/4492> (Última consulta: 18/07/2019).

Moreno Fernández, Agustín (2016). El giro hermenéutico sacrificial en la teoría de lo sagrado de René Girard. En S. Bara y A. Sánchez (eds.). El amor, lo sagrado y lo político. Madrid: Universidad Pontificia Comillas, pp. 231-262.

Morin, Edgar (1983). Peut-on concevoir une science de l'autonomie? En Dumouchel, Paul et Dupuy, Jean-Pierre (dir.). L'auto-organisation. De la physique au politique. Paris: Seuil, pp. 317-325. 
Desmitificación y revalorización de la libertad... - A. Moreno Fernández

Morin, Edgar (2000). Antropología de la libertad. Gazeta de Antropología [en línea], n 16, artículo 01. <http://www.gazeta-antropologia.es/?p=3349> (Última consulta: 18/07/2019).

Morin, Edgar (2001). La Méthode. 5. L'humanité de l'humanité. Paris: Seuil.

Morin, Edgar (2013). Mes philosophes. Paris: Fayard/Pluriel.

Morin, Edgar (2017). Connaissance ignorance mystère. Paris: Fayard.

Oughourlian, Jean-Michel (2009). My Life with René. En Goodhart, Sandor; Jørgensen, Jørgen ; Ryba, Tom and Williams, James G. (eds.). For René Girard. Essays in Friendship and in Truth. Michigan State University Press, pp. 51-56.

Oughourlian, Jean-Michel (2017). Cet autre qui m’obsède. Paris: Albin Michel.

Renaut, Alain (2010). Découvrir la philosophie: Le sujet. Paris: Odile Jacob.

Williams, James G. (1996). The Anthropology of the Cross: A Conversation with René Girard. En Girard, René. The Girard Reader. Williams, James G. (ed.). New York: Crossroad Herder, pp. 262-288. 